Scientific paper

\title{
Effect of ZnO on the Thermal Degradation Behavior of Poly(Methyl Methacrylate) Nanocomposites
}

\author{
Dajana Japić, ${ }^{1}$ Marjan Marinšek ${ }^{*, 2}$ and Zorica Crnjak Orel ${ }^{1}$ \\ ${ }^{1}$ National Institute of Chemistry, Hajdrihova 19, 1001 Ljubljana, Slovenia \\ ${ }^{2}$ University of Ljubljana, Faculty of Chemistry and Chemical Technology, Večna pot 113, 1000 Ljubljana, Slovenia \\ * Corresponding author: E-mail: marjan.marinsek@fkkt.uni-lj.si
}

Phone: 0038614798589

Received: 04-02-2016

In the memory of Janez (Janko) Jamnik our dear friend and co-worker.

\begin{abstract}
The influence of $\mathrm{ZnO}$ nanoparticles on the thermal degradation behavior of poly(methyl methacrylate) (PMMA) was tested using thermoanalytical techniques. The studied materials were investigated using TG, DTA, EGA, XRD, SEM and TEM. The $\mathrm{ZnO}$ nanoparticles were synthesized via precipitation by adding $\mathrm{LiOH}$ into $\mathrm{Zn}^{2+}$ water/ethylene glycol solutions. The ZnO-PMMA nanocomposites were prepared by adding the appropriate amount of $\mathrm{ZnO}$ into MMA and subsequent MMA radical polymerization. According to the experimental results and model-free isoconversional activation energy calculations, the addition of $\mathrm{ZnO}$ into PMMA played a double role. The $\mathrm{ZnO}$ concentrations up to $0.15 \%$ stabilized the composite by shifting the degradation interval toward higher temperatures and increasing the apparent activation energy relative to pure PMMA. At higher concentrations, the catalytic effect of $\mathrm{ZnO}$ started to prevail and was reflected in the lower temperature intervals of intense PMMA degradation and lower apparent activation energy. The addition of $\mathrm{ZnO}$ generally did not change the nature of the PMMA decomposition process.
\end{abstract}

Keywords: ZnO-PMMA nanocomposites, thermal properties, activation energy, electron microscopy, thermogravimetric analysis (TGA)

\section{Introduction}

The potential of using nanometer-scale inorganic particles in a polymer matrix has recently been extensively investigated in several applications, e.g. civil and electrical engineering, building and transportation. Such composites offer the potential to create new materials with improved thermal, electrical, mechanical, optical and fire-resistant properties, which arise from the synergies between the components. ${ }^{1-5}$ Among the papers published about this subject, it appears that the majority of the work performed particularly concerns composites of poly(methyl methacrylate) (PMMA) and oxide ceramic filler. ${ }^{6-8}$ PMMA is an optically clear amorphous thermoplastic. It is widely used as a substitute for inorganic glass, because it shows higher impact strength and undergoes ductile rather than brittle fracturing. Compared with inorganic glass, PMMA has some advantages, such as transmission of more light, and has lower density than silica glass (1.19 and $2.20 \mathrm{~g} \mathrm{~cm}^{-3}$, respectively). ${ }^{9}$ However, PMMA shows poor thermal stability, which restricts it from high-temperature applications. Significant research has been performed in order to improve the thermal stability of PMMA by mixing it with various inorganic fillers. Among inorganic fillers added to PMMA, silica was the most widely investigated. ${ }^{10-14}$ The thermal degradation of such composites was a prime areas of investigation. It was shown that the addition of silica into PMMA improves thermal stability of the composites. This improved thermal stability was explained by the hindered mobility of the polymer chains due to the presence of filler, ${ }^{15}$ the ability of silica nanoparticles to trap radicals during PMMA degradation and to act as a gas barrier preventing the degradation products from diffusing out of the composite, ${ }^{14}$ or through a hydrogen-bonding interaction between carbonyl groups in PMMA and hydroxyl groups of the silica surface, ${ }^{16}$ where hydrogen bonds interrupt the depolymerization of the polymer 
chains. Similarly to silica, the addition of $\mathrm{Fe}_{2} \mathrm{O}_{3}$ and $\mathrm{TiO}_{2}$ nanoparticles into PMMA also influence the composite thermal stability. The improved thermal stability observed in $\mathrm{Fe}_{2} \mathrm{O}_{3} / \mathrm{TiO}_{2}$-PMMA composites was the result of two main factors: i) the presence of the nanoparticles restricted the mobility of polymer chains, and ii) adsorption of the PMMA on the oxide surface via metoxycarbonyl groups. ${ }^{17,18}$ Subsequently, it was shown that relatively high additions of $\mathrm{TiO}_{2}$ nanoparticles into PMMA also play a catalytic role on the polymer thermal degradation. ${ }^{19,20}$ This catalytic effect was explained through the interaction of the methoxy group of the methacrylate with the hydroxyl groups present at the surface of the oxide particles.

In recent years, the addition $\mathrm{ZnO}$ into PMMA has also been intensively studied in order to make functional nanocomposites. ${ }^{21-27} \mathrm{ZnO}$ is an environmentally friendly, important and attractive semiconducting material. It has drawn enormous research attention due to its distinguished properties in optics, photonics and electronics. ${ }^{28}$ The combination of these two materials has many potential applications, including antireflection coatings, transparent barrier/protective layers, and as flame-retardant materials. $\mathrm{ZnO}$ is also a semiconductor with an optical band gap in the UV region that also makes it useful as an efficient absorber of UV radiation. ${ }^{29}$ Moreover, $\mathrm{ZnO}$ can be simply obtained through wet chemistry, which offers it a potential viable route to achieve uniform dispersion in polymer matrices through solution mixing. In studying the thermal stability of ZnO-PMMA composites, it has been shown that $\mathrm{ZnO}$ addition has a profound effect on the thermal degradation of the composite. ${ }^{1,30}$ Liu et al. ${ }^{31}$ prepared PMMA/ZnO nanocomposites through in situ polymerization of MMA and organic modified nanoparticles. The thermal stability and UV absorption of the nanocomposites were enhanced as $\mathrm{ZnO}$ concentration increased. Similar results were also reported by Demir et al. ${ }^{32}$ who studied the improved thermal stability of PMA/ZnO nanocomposites compared with the blends of PMMA and $\mathrm{ZnO}$. Liufu et al. ${ }^{33}$ also investigated the thermal degradation of polyacrylate/ $\mathrm{ZnO}$ blends and proposed that the $\mathrm{ZnO}$ particles have a role in both stabilization and destabilization depending on the temperature region. Generally, the role of $\mathrm{ZnO}$ on the thermal stability of $\mathrm{Zn}$ O-PMMA can be explained through the same relatively developed mechanisms, such as the barrier effect, trapping radicals, char formation and catalytic effect, as described for $\mathrm{SiO}_{2}$-PMMA or $\mathrm{TiO}_{2}$-PMMA composites. $^{13,17,34-36}$

Since few research reports focused on thermal behavior of ZnO-PMMA composites, the aim of this work was to demonstrate the catalytic effect of $\mathrm{ZnO}$ nanoparticles in the path of PMMA thermal degradation. For this purpose, key degradation products were determined and some kinetic aspects were investigated via a model-free method.

\section{Material and Methods}

\section{1. Used Chemicals}

All reagents used for synthesis were of an analytical reagent grade. To avoid hydrolysis upon storage, fresh stock aqueous solutions were prepared from $\mathrm{Zn}\left(\mathrm{NO}_{3}\right)_{2} \cdot 6 \mathrm{H}_{2} \mathrm{O}$ (98\% Merck), ethylene glycol $(99.5 \%$ Sigma-Aldrich) and lithium hydroxide (98\% Sigma-Aldrich). For in situ and ex situ coating of $\mathrm{ZnO}$ particles, tetraethyl orthosilicate (TEOS) (Sigma-Aldrich), 25\% $\mathrm{NH}_{3(\mathrm{aq})}$ solution (Merck) and absolute EtOH (SigmaAldrich) were used. Methyl methacrylate (MMA) (99\% Sigma-Aldrich), bis (4-t-butylcyclohexyl)-peroxydicarbonate (P-16) and dilauroyl peroxide (LPO) were used for the preparation of $\mathrm{ZnO} / \mathrm{PMMA}$ nanocomposites.

\section{2. Synthesis of Spherical $\mathrm{ZnO}$ Nanoparticles}

Prior to $\mathrm{ZnO}$ synthesis, the mother solution was prepared by mixing $\mathrm{Zn}\left(\mathrm{NO}_{3}\right)_{2(\mathrm{aq})}, \mathrm{EG}_{(\mathrm{aq})}$ and $\mathrm{LiOH}_{(\mathrm{aq})}$. In the mother solution, the initial concentrations of $\mathrm{Zn}^{2+}$ and $\mathrm{Li}^{+}$ ions were $0.1 \mathrm{M}$ and the volume ratio of water-to-ethylene glycol was $V\left(\mathrm{H}_{2} \mathrm{O}\right): V(\mathrm{EG})=1: 5$ The syntheses of $\mathrm{ZnO}$ nanoparticles were carried out in a $250 \mathrm{~mL}$ flask without stirring at $100{ }^{\circ} \mathrm{C}$, for 2 hours. Firstly, $\mathrm{Zn}^{2+}$ and $\mathrm{LiOH}$ solutions in $150 \mathrm{~mL}$ of mixed solvents were prepared and heated to $100{ }^{\circ} \mathrm{C}$. After the hydrolysis reaction was completed, the resulting white precipitate of $\mathrm{ZnO}$ was centrifuged, washed with water four times and dried in air at room temperature or re-dispersed in EtOH. In depth report how preparation conditions influence final $\mathrm{ZnO}$ morphology can be found elsewhere. ${ }^{37}$

\section{3. The Preparation of Silica-coated $\mathrm{ZnO}$ Nanoparticles by ex-situ Method}

Part of the synthesized $\mathrm{ZnO}$ nanoparticles was further functionalized by coating them with silica. In a typical ex-situ coating process, the dried $\mathrm{ZnO}$ was re-dispersed in $10 \mathrm{~mL}$ EtOH and $4 \mathrm{~mL}$ MQ water, then $\mathrm{NH}_{3(\mathrm{aq})}$ was added to the re-dispersed $\mathrm{ZnO}$ solution, and finally the appropriate quantity of TEOS to reach $C($ TEOS $)=0.048 \mathrm{M}$ was admixed. The coating process was carried out at room temperature for 1 hour in an ultrasonic bath, as suggested in the literature. ${ }^{38}$ After the procedure was completed, the final product was purified in $\mathrm{EtOH}$ and dried in air at room temperature.

\section{4. Synthesis of PMMA}

PMMA (sample A) was prepared by chain growth radical polymerization. Prior to polymerization reaction, the initiators P-16 (0.25 wt.\%) and LPO (0.25 wt.\%) were added to MMA. The polymerization of MMA was carried out in a water bath at $60{ }^{\circ} \mathrm{C}$ for 1 hour. The synthesized 
PMMA was poured into glass plates and placed in an oven for 2 hours at $55{ }^{\circ} \mathrm{C}$ and subsequently for 10 minutes at $120^{\circ} \mathrm{C}$. Finally, the PMMA sheets were separated from the glass plate moulds.

\section{5. Preparation of $\mathrm{ZnO} / \mathrm{PMMA}$ Nanocomposites}

0.1 wt.\% of bare (sample B2) or coated $\mathrm{ZnO}$ powders (sample $\mathrm{C}$ ) were suspended in $5 \mathrm{~mL}$ of MMA in a centrifuge tube. The suspensions were sonicated (continuous waves) for 20 minutes prior to the addition of initiators. The polymerization of MMA was conducted as described above. Samples with $0.05 \%, 0.15 \%$ and $0.20 \%$ (named sample B1, B3 and B4, respectively) were prepared in the same manner.

\section{6. Products Characterization}

The obtained bare or coated $\mathrm{ZnO}$ powders were characterized according to their morphological characteristics with a field emission scanning electron microscope (FE-SEM, Zeiss UltraPlus) with the ability to work in STEM mode. TEM observations were carried out in a transmission electron microscope operated at $200 \mathrm{kV}$ (JEM-2100, JEOL) which was equipped with EDX. TEM samples were prepared by dispersing the powders in ethanol, using ultrasonification followed by the deposition of the obtained suspension on carbon-coated copper grids. X-ray powder diffraction analyses (XRD, Siemens D-500 $\mathrm{X}$-ray diffractometer) were carried out with $\mathrm{Cu}-\mathrm{K} \alpha$ radiation $(\lambda=1.54 \AA)$ in the range $2 \theta$ between $20^{\circ}$ and $70^{\circ}$ using an XPert Pro X-ray diffractometer. Thermo-gravimetric decompositions of PMMA or ZnO-PMMA composites were performed using $\sim 50 \mathrm{mg}$ of the sample and a NETZSCH STA 449 F3 set-up with a microbalance having a sensitivity of $\pm 0.1 \mathrm{~g}$ coupled with QMS $403 \mathrm{C}$ system. The experiments were carried out in a constant flow of synthetic air $\left(50 \mathrm{~mL} / \mathrm{min} ; \mathrm{Ar}-\mathrm{O}_{2}-20\right.$ vol. $\left.\% \mathrm{O}_{2}\right)$ under non-isothermal conditions $\left(30-600^{\circ} \mathrm{C}\right)$ with heating rates $\beta$ from $2 \mathrm{~K} / \mathrm{min}$ to $10 \mathrm{~K} / \mathrm{min}$. Partial kinetic analyses of the $\mathrm{ZnO} / \mathrm{PMMA}$ thermal decomposition were calculated using the non-linear isoconversional method developed by Vyazovkin. ${ }^{39}$ The isoconversional analysis is based on a model kinetic equation (1):

$$
\frac{\partial \alpha}{\partial t}=f(\alpha) k_{\alpha} \exp \left(-\frac{E_{a}}{R T}\right)
$$

where $\alpha$ is conversion degree of the degradation reaction, $E_{\mathrm{a}}$ is the apparent activation energy $\left(\mathrm{J} \mathrm{mol}^{-1}\right), k \alpha$ is the pre-exponential factor $\left(\mathrm{s}^{-1}\right)$ and $f(\alpha)$ is the reaction model [16]. From the above kinetic model, the linear dependence of $\operatorname{In} \beta$ vs. $1 / T$ may be recognized. Using the Doyle approximation, the slope in the $\operatorname{In} \beta$ vs. $1 / T$ diagram represents a value of $1.052 E_{\mathrm{a}} / \mathrm{R}$. The UV-VIS spectra of $\mathrm{ZnO} / \mathrm{PMMA}$ nanocomposites were measured on solid plates prepared from pure PMMA, non-coated $\mathrm{ZnO}$ and silica-coated $\mathrm{Zn}$ $\mathrm{O}$ particles into PMMA using the Perkin Elmer Lambda 950 UV-VIS spectrometer in the spectral range between 250 and $800 \mathrm{~nm}$.

\section{Results and Discussion}

Powder XRD analysis of the prepared nanoparticles (Figure 1) revealed that all major peaks correspond to $\mathrm{Zn}$ $\mathrm{O}$ zincite (JCPDS 01-079-2205, zinc oxide). $\mathrm{ZnO}$ is the only crystalline phase present in the sample. The average crystallite size calculated from the (100) diffraction plane is $14.3 \mathrm{~nm}$.

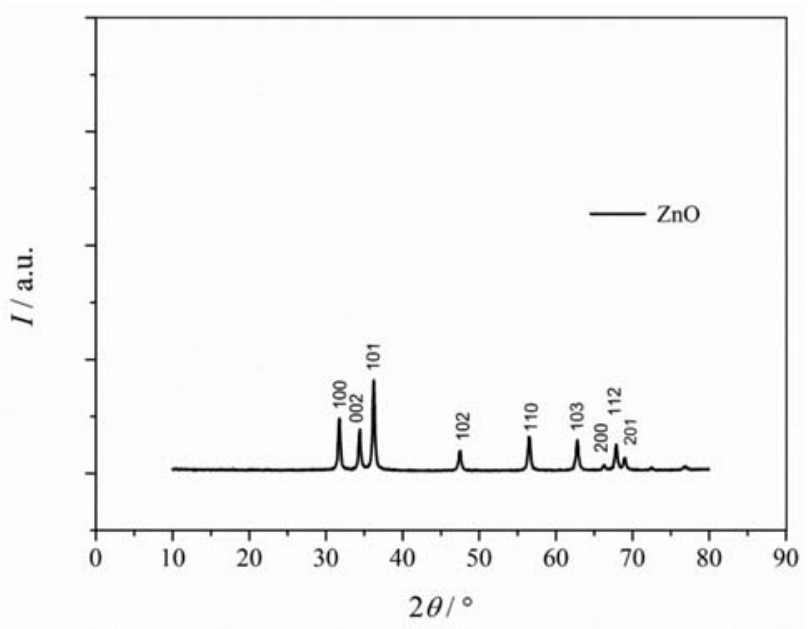

Figure 1. XRD pattern of the prepared $\mathrm{ZnO}$ nanoparticles

The morphology of the prepared $\mathrm{ZnO}$ nanoparticles (bare or silica-coated) was determined via electron microscopy. SEM and TEM micrographs are presented in Fig. 2. The micrograph reveals spherical $\mathrm{ZnO}$ nanoparticles (diameter $\sim 10-20 \mathrm{~nm}$ ) (Fig. 2a) and $\mathrm{ZnO}$ nanoparticles coated with a layer of silica $\sim 8 \mathrm{~nm}$ (Fig. 2b). The silica coating had no influence on the morphology of the $\mathrm{ZnO}$ nanoparticles.

Introduction of the prepared nanoparticles into PMMA resulted in rather homogenous and uniform dispersion (Fig. 3). Neither areas of highly agglomerated solid particles nor larger areas clear of $\mathrm{ZnO}$ addition are observed. Such ZnO-PMMA composites are used for their thermo-oxidative degradation study.

The thermal stability of the pure PMMA or $\mathrm{ZnO}$ PMMA nanocomposites is studied using TG-DTA-QMS experiments (Fig. 4). The basic idea is to show that the addition of $\mathrm{ZnO}$ into PMMA alters the thermal decomposition of such composites, either from a chemical point of view or/and with respect to the temperature interval of the 

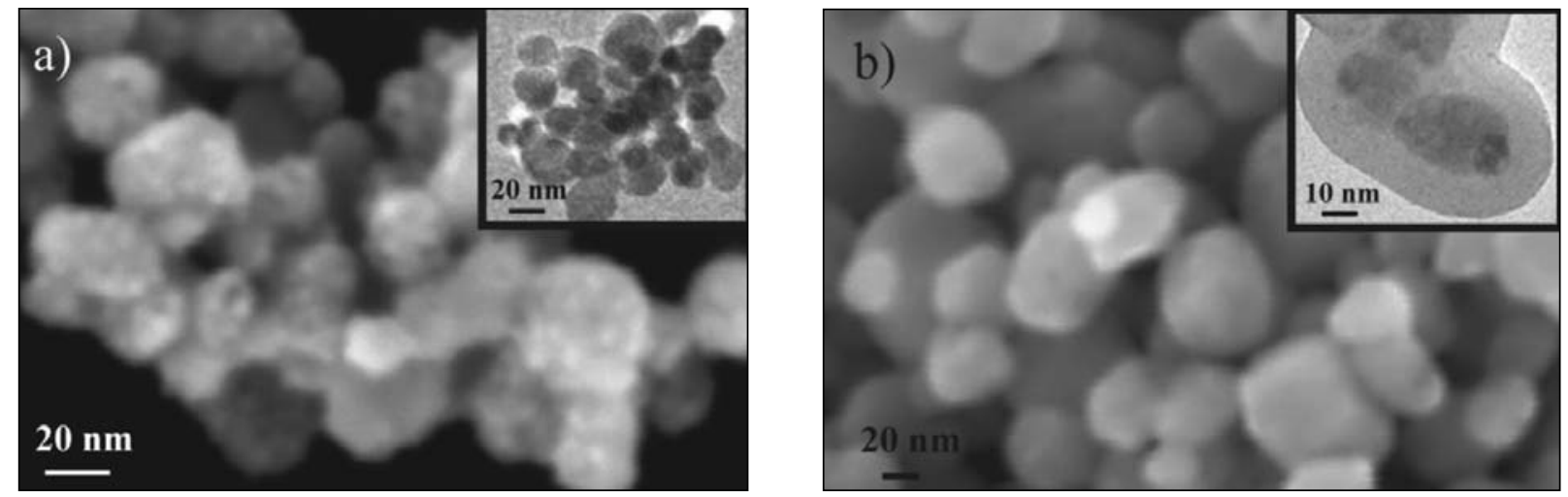

Figure 2. SEM and TEM micrographs of a) bare $\mathrm{ZnO}$ and b) silica-coated spherical $\mathrm{ZnO}$ nanoparticles

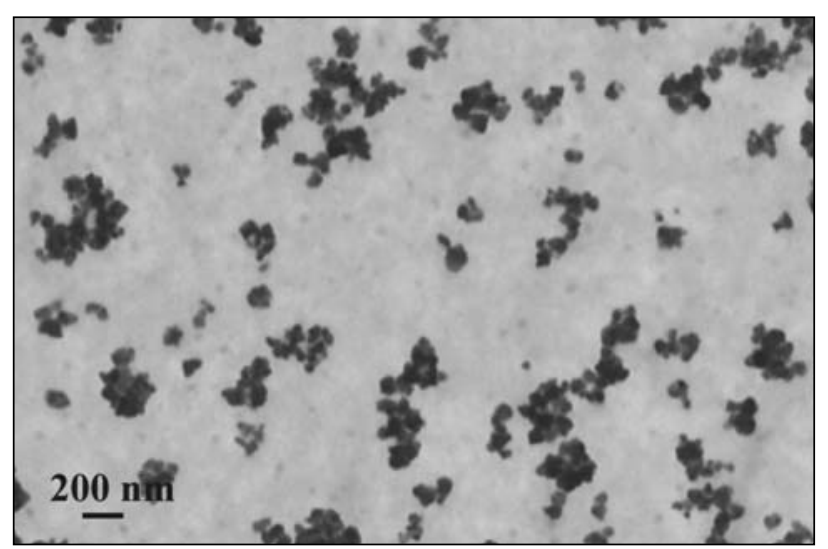

Figure 3. $\mathrm{ZnO}$ distribution in PMMA (STEM image)

decomposition. Although the TG-DTA curves describing thermal decomposition of samples A-C are rather similar, there are some distinguishing differences among them. Pure PMMA (sample A) decomposes in one broad interval from $\sim 230{ }^{\circ} \mathrm{C}$ to $\sim 380{ }^{\circ} \mathrm{C}$ (Fig. 4a). According to the DTG and DTA curves, at least two steps may be recognized inside this broad interval. The first step at around 300 ${ }^{\circ} \mathrm{C}$ is rather vague while the second step, with its peak temperature $\sim 355{ }^{\circ} \mathrm{C}$, may be clearly identified. The chain scission of sample A in synthetic air is practically complete, since less than $0.01 \%$ residue remains after the analysis. Volatile products of the decomposition followed by the QMS reveal the presence of $\mathrm{H}_{2} \mathrm{O}(\mathrm{m} / \mathrm{e} \mathrm{18}), \mathrm{CO}_{2}(\mathrm{~m} / \mathrm{e}$ 44), $\mathrm{CO}$ (m/e 28), $\mathrm{MeOH}$ (m/e 31), propanoic acid methyl ester (PAME) with a characteristic signal at $\mathrm{m} / \mathrm{e} 88$ and methacrylic acid (MA) with characteristic signal m/e 41. All volatile products are evolved continuously throughout the degradation path and their relative intensities are in accordance with the DTG curve.

If bare $\mathrm{ZnO}$ nanoparticles are admixed to PMMA (sample B2), the temperature interval of the thermal decomposition does not change significantly with respect to pure PMMA (Figs $4 \mathrm{a}$ and $4 \mathrm{~b}$ ). It is shifted to somewhat higher values but remains inside the range from $\sim 240{ }^{\circ} \mathrm{C}$ to $\sim 400{ }^{\circ} \mathrm{C}$. However, the profiles of the TG curve and, consequently, the DTG and DTA curves change. In the latter case, inside the decomposition interval of ZnO-PMMA, the DTG curve predicts one additional distinctive step. The additional step with peak temperature at $\sim 295{ }^{\circ} \mathrm{C}$ is reflected in a relatively quick mass change and is not characteristic for the thermal decomposition of pure PMMA without the addition of $\mathrm{ZnO}$. The remaining (main) decomposition steps with peak temperatures of $\sim 320^{\circ} \mathrm{C}$ and $\sim 355^{\circ} \mathrm{C}$ are similar to pure PMMA decomposition. All decomposition steps are exothermic and may also be recognized in the DTA curve. Volatile products during thermal decomposition of ZnO-PMMA are generally the same as in the case of pure PMMA. However, the relative intensities of the various detected $\mathrm{m} / \mathrm{e}$ signals change significantly with temperature if $\mathrm{ZnO}$ is added into PMMA. The $\mathrm{ZnO}$ addition particularly intensifies signals $\mathrm{m} / \mathrm{e} 88$ (PAME) and m/e 41 (MA) during the first decomposition step at $\sim 295^{\circ} \mathrm{C}$. Such behavior of $\mathrm{ZnO}$ clearly demonstrates its catalytic nature toward PMMA thermal decomposition. It is evident that the addition of $\mathrm{ZnO}$ does not change the nature of the decomposition process. Instead, it influences temperature intervals of intense degradation especially during the early stages. From this perspective, $\mathrm{ZnO}$ in PMMA behaves similarly to $\mathrm{TiO}_{2}$. $\mathrm{TiO}_{2}$ was also reported to act catalytically for PMMA thermal degradation that is accompanied by $\mathrm{MeOH}, \mathrm{PAME}$ and MA evolution. ${ }^{16}$

To further clarify the role of $\mathrm{ZnO}$ during the thermal decomposition of PMMA, silica-coated $\mathrm{ZnO}$ nanoparticles were also incorporated into PMMA. As expected from the fact that silica does not catalytically promote the thermal decomposition of PMMA, the sequences of evolved gases for samples $\mathrm{C}$ (silica-coated ZnO-PMMA) and A (pure PMMA) are rather similar (Figs $4 \mathrm{a}$ and $4 \mathrm{c}$ ). The coating of $\mathrm{ZnO}$ nanoparticles with silica substantially diminish the degradation step at $\sim 290^{\circ} \mathrm{C}$. This first degradation step is not negligible, however; it is ascribed to the fact that the minor part of $\mathrm{ZnO}$ nanoparticles may be poorly coated. 


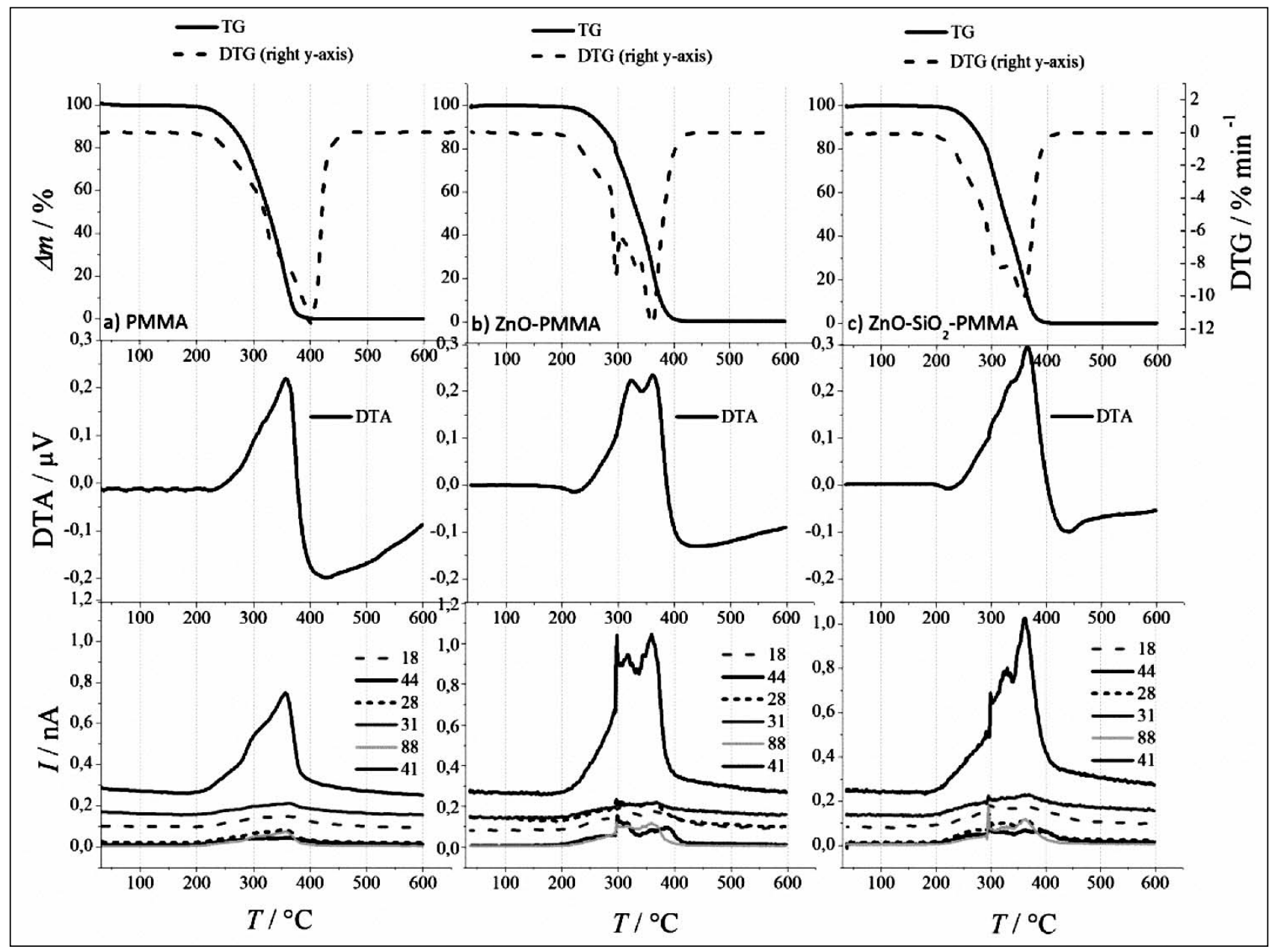

Figure 4. TG-DTG-DTA curves and QMS signals for thermal decomposition of samples A, B2 and C

The detected volatile products during the ZnO-PMMA decomposition suggest acid-base interaction between the $\mathrm{ZnO}$ surface and PMMA matrix. This interaction involves acidic electron-accepting $\mathrm{OH}$ groups at the $\mathrm{ZnO}$ surface and basic electron-donating carbonyl functional groups of PMMA. Such interaction between $\mathrm{COO}^{-}$of PMMA and metal-oxide surface is accompanied by Me$\mathrm{OH}$ elimination and has been proposed for several metal oxides, including $\mathrm{Al}_{2} \mathrm{O}_{3},{ }^{40} \mathrm{Mg}(\mathrm{OH})_{2},{ }^{41} \mathrm{TiO}_{2}{ }^{19}$ and $\mathrm{ZnO}^{33}$ Subsequently, at the $\mathrm{ZnO}$ surface, MA and PAME are generated by random chain scission.

In addition to the catalytic effect of $\mathrm{ZnO}$ nanoparticles during the early stages of PMMA thermal degradation, their stabilizing role must also be considered. It is evident from Fig. 5 that the small addition of $\mathrm{ZnO}$ or silica-coated $\mathrm{ZnO}$ nanoparticles into PMMA shifts the temperature region towards somewhat higher temperatures. Normally, the enhanced thermal stability of such a composite is explained by means of polymer chain mobility restriction due to steric hindrance caused by the presence of solid particles or simply by the fact that metal oxide particles have higher thermal conductivity and greater heat capa- city values than PMMA and thus absorb the heat transmitted from the surroundings and retard the direct thermal impact to the polymer backbone. ${ }^{42,43}$ Such physical causes for the improved thermal stability of the composite are also in accordance with the measured data. Specifically, the temperature regions of PMMA decomposition for samples B2 and C are practically identical. The only difference among these two samples, regarding their thermal stability, arises from already described catalytic behavior of $\mathrm{ZnO}$ around $295{ }^{\circ} \mathrm{C}$. Above or below the region of $\mathrm{ZnO}$ catalytic activity, both TG curves progress identically, indicating the same impact on PMMA thermal degradation for $\mathrm{ZnO}$ and silica-coated $\mathrm{ZnO}$ nanoparticles.

Stabilizing or destabilizing effects of metal oxide addition into PMMA on the thermal degradation of the composite should have its reflection in degradation kinetic parameters. In order to determine apparent activation energy $E_{\mathrm{a}}$ of PMMA or PMMA-composite degradation, dynamic weight loss data at various $\beta$ from the TG analysis were used. The results of $E_{\mathrm{a}}$ vs degree of conversion $(\alpha)$ relationship are shown in Fig. 6. It appears that the addition of $0.1 \%$ of solid nanoparticles (bare $\mathrm{ZnO}$ or coated 


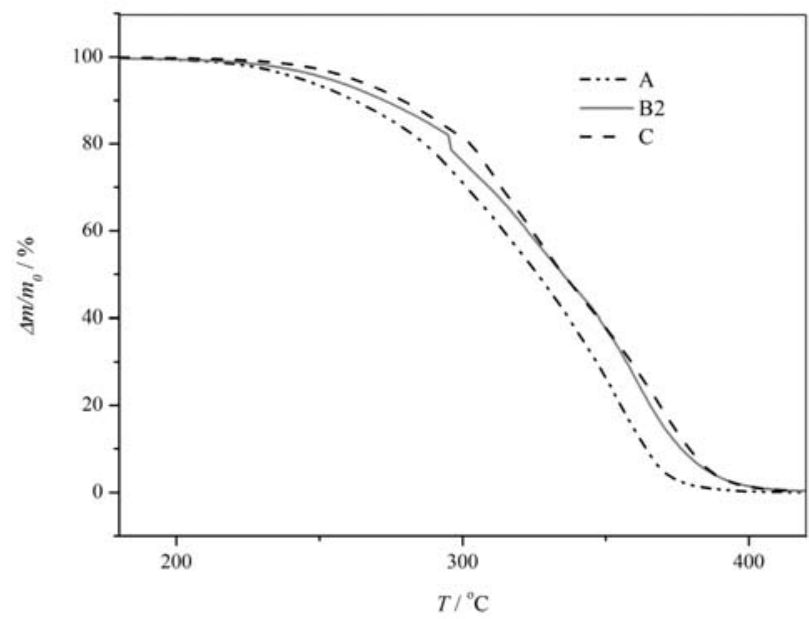

Figure 5. TG-DTG curves for a) filler free PMMA (Sample A), b) PMMA with the addition of nanosized $\mathrm{ZnO}$ (Sample B2) and c) PMMA with the addition of silica-coated nanosized $\mathrm{ZnO}$ (Sample C)

$\mathrm{ZnO}$ ) raises $E_{\mathrm{a}}$ of the material's thermal degradation. Such a result is in accordance with the already described stabilizing effect during thermal degradation when solid particles are added into PMMA. ${ }^{30-32}$ However, by comparing the average $E_{\mathrm{a}}$ values for samples $\mathrm{A}-\mathrm{C}$, an interesting result is observed. The $E_{\mathrm{a}}$ of pure PMMA was calculated as $145 \mathrm{~kJ} / \mathrm{mol}$. If $0.1 \%$ bare $\mathrm{ZnO}$ is admixed into PMMA, the $E_{\mathrm{a}}$ of thermo-oxidative degradation increases to $155 \mathrm{k}$ $\mathrm{J} / \mathrm{mol}$. In contrast, if $0.1 \%$ silica-coated $\mathrm{ZnO}$ is added into PMMA, the $E_{\mathrm{a}}$ value further increases to $190 \mathrm{~kJ} / \mathrm{mol}$. Rather noticeable differences between the calculated $E_{\mathrm{a}}$ values of samples A-C indicate the double role of $\mathrm{ZnO}$ in the ZnO-PMMA composite. In addition to the stabilizing effect that increases the $E_{\mathrm{a}}$ value (comparison between samples A and B2), $\mathrm{ZnO}$ also acts catalytically toward PMMA degradation by considerably lowering the $E_{\mathrm{a}}$ value if sample $\mathrm{B} 2$ is compared to sample $\mathrm{C}$.

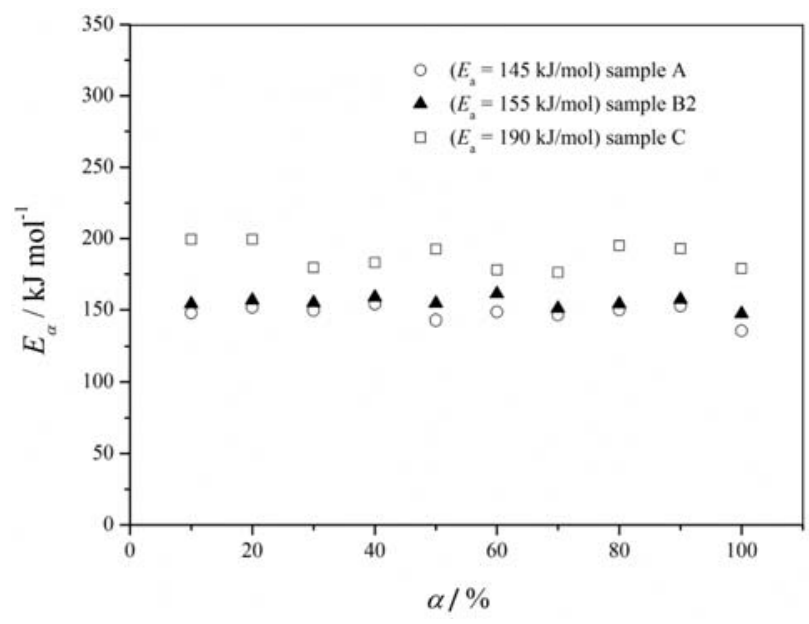

Figure 6. $E_{a}$ vs $\alpha$ relationship for PMMA or PMMA-composites thermal decomposition
Since the addition of $\mathrm{ZnO}$ into PMMA simultaneously stabilizes and destabilizes the thermal stability of PMMA, a critical addition of $\mathrm{ZnO}$ was further systematically investigated in order to distinguish between these two opposite effects. For this purpose, a series of $\mathrm{ZnO}$ PMMA composites were prepared with the addition of $\mathrm{ZnO} 0.05 \%, 0.10 \%, 0.15 \%$ and $0.20 \%$ (samples B1, B2, $\mathrm{B} 3$ and B4, respectively) and submitted to further thermal analysis. The TG curves of the B-series ZnO-PMMA composites are shown in Fig. 7. Evidently, any addition of $\mathrm{ZnO}$ into PMMA shifts the TG curves to higher decomposition temperature intervals with respect to pure PMMA. Therefore, $0.20 \%$ of $\mathrm{ZnO}$ in PMMA stabilizes thermal stability of the composite for $\sim 25^{\circ} \mathrm{C}$ by shifting the main decomposition peak from $\sim 350^{\circ} \mathrm{C}$ (pure PMMA) to $\sim 375$ ${ }^{\circ} \mathrm{C}$ (sample B4). Moreover, with increasing amounts of $\mathrm{ZnO}$ the additional TG step (at $\sim 295{ }^{\circ} \mathrm{C}$ in the case of sample B2) slowly starts to form.

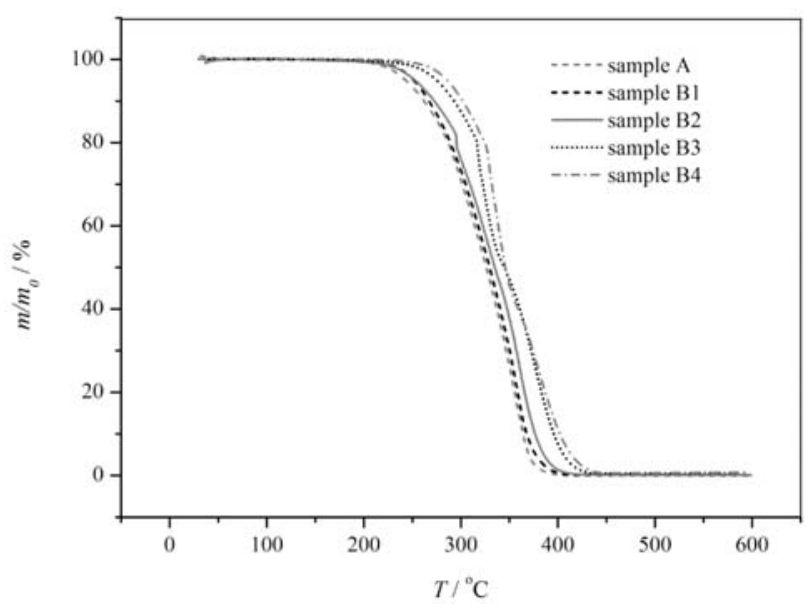

Figure 7. TG curves of PMMA and B-series of ZnO-PMMA composites with various addition of $\mathrm{ZnO}$

When B-series samples are submitted to the Vyazovkin method of partial kinetic analysis, the $E_{\mathrm{a}}$ values are calculated (Fig. 8). It appears that the addition of $0.05 \% \mathrm{ZnO}$ into PMMA (Sample B1) does not change the average $E_{\mathrm{a}}$ value of the composite thermal degradation relative to pure PMMA. The highest $E_{\mathrm{a}} 215$ value $\mathrm{kJ} / \mathrm{mol}$ was determined for sample $\mathrm{B} 3(0.15 \% \mathrm{ZnO})$, while further increased amount of $\mathrm{ZnO}$ again slightly lowered the $E_{\mathrm{a}}$ value to $190 \mathrm{~kJ} / \mathrm{mol}$ (Sample B4). Such behavior may be explained by means of the stabilizing/catalytic effect of $\mathrm{ZnO}$ on the thermal stability of PMMA. With relatively small additions of $\mathrm{ZnO}$, its stabilizing effect prevails over the catalytic activity. The smallest addition of $\mathrm{ZnO}$ into PMMA apparently represents sufficient steric hindrance for polymer chain mobility; however, the $\mathrm{ZnO} / \mathrm{PMMA}$ interface simultaneously remains relatively low, not contributing significantly to the composite thermal degradation. The stabilizing effect reaches its 


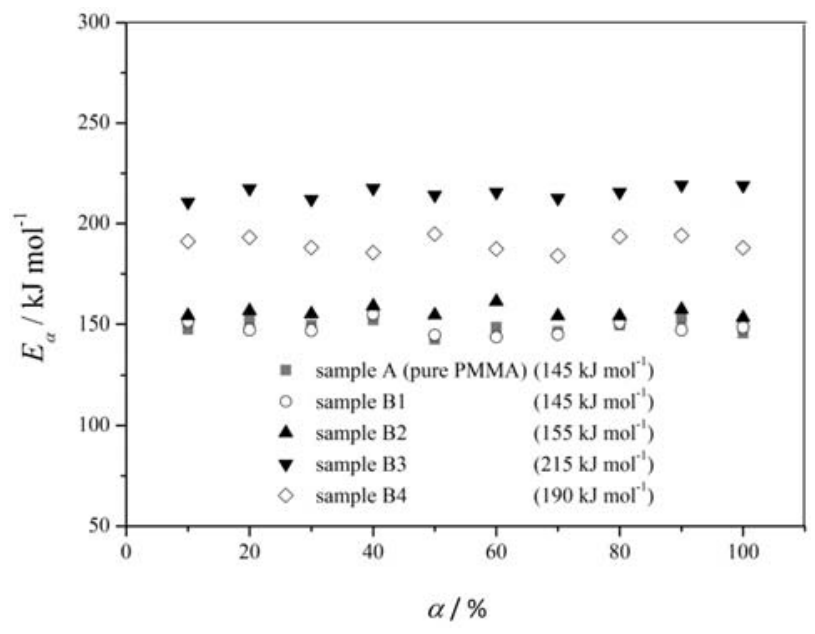

Figure 8. $E_{\mathrm{a}}$ vs $\alpha$ relationship for B-series ZnO-PMMA composites (PMMA is added for the comparison)

peak when $0.15 \% \mathrm{ZnO}$ is dispersed throughout PMMA. In contrast, the catalytic effect of $\mathrm{ZnO}$ becomes significant above $0.15 \%$ due to the increased $\mathrm{ZnO} / \mathrm{PMMA}$ interface.

Another important characteristic of ZnO-PMMA composites is their transparency for UV and visible light. For practical applications final material should absorb UV light but transmit visible light. As shown in Figure 9 pure PMMA (sample A) is transparent for UV and visible light. However, small addition of $\mathrm{ZnO}$ into PMMA (sample B2) practically completely absorbs UV light. At the same time the material remains transparent for visible light. Similar effect is achieved also when silica coated $\mathrm{ZnO}$ nanoparticles are added into PMMA (sample C). Such material likewise absorbs UV light due to $\mathrm{ZnO}$ content, whereas in the region of visible light silica-coated ZnO/PMMA nanocomposite exhibit only slightly lower transmittance then $\mathrm{ZnO} / \mathrm{PMMA}$ composite.

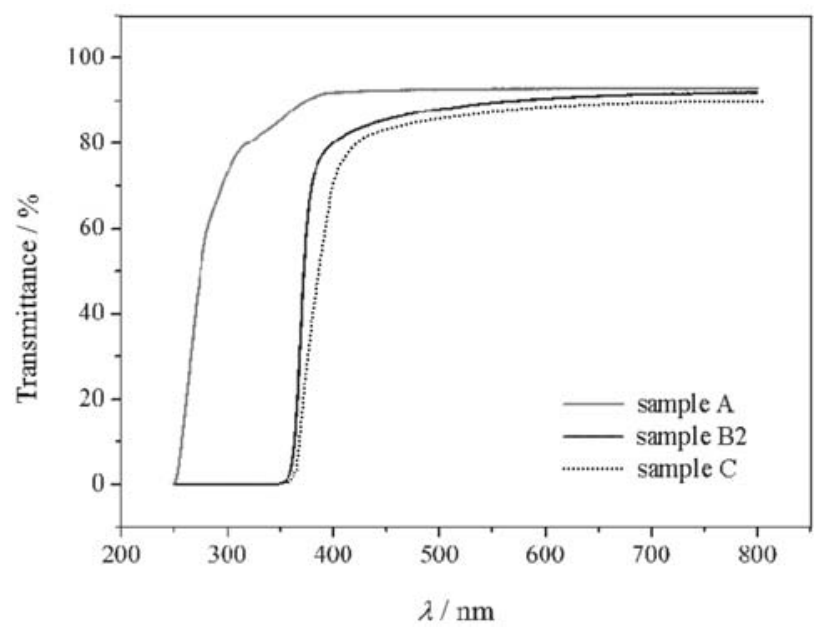

Figure 9. Light transmittance as a function of wavelength of pure PMMA (sample A), nanocomposite ZnO/PMMA (sample B2), silica-coated ZnO/PMMA (sample C)

\section{Conclusion}

The thermal properties of ZnO-PMMA nanocomposites are investigated via TG-DTA-EGA analyses. The filler-free PMMA thermally decomposes in one broad interval composed of at least two consecutive and partially overlaying steps. Volatile products of the decomposition are determined as $\mathrm{H}_{2} \mathrm{O}, \mathrm{CO}_{2}, \mathrm{CO}, \mathrm{MeOH}, \mathrm{PAME}$ and $\mathrm{MA}$. All volatile products are evolved continuously throughout the degradation path.

By adding $\mathrm{ZnO}$ into PMMA, two opposite effect are recognized. Any addition of $\mathrm{ZnO}$ into PMMA thermally stabilizes the composite by delaying the occurrence of major polymer cracking and thus shift the TG curves to higher decomposition temperatures. The stabilizing role of $\mathrm{ZnO}$ is explained by means of physical grounds, i.e. steric hindrance caused by $\mathrm{ZnO}$ for polymer chain mobility and heat absorption by $\mathrm{ZnO}$ through relatively higher thermal conductivity and greater heat capacity. In contrast, during the early stages of PMMA thermal decomposition, $\mathrm{ZnO}$ acts also catalytically by intensifying the decomposition rate. Through the detected volatile products during the ZnOPMMA decomposition, the catalytic acidbase interaction between $\mathrm{ZnO}$ surface and PMMA matrix is suggested.

The critical addition of $\mathrm{ZnO}$ into PMMA, in which the catalytic effect prevails over the stabilizing effect due to increased $\mathrm{ZnO} / \mathrm{PMMA}$ interface, is determined between $0.15-0,20 \% \mathrm{ZnO}$. Generally, the addition of $\mathrm{ZnO}$ does not change the nature of the decomposition process. Instead, it influences temperature intervals of intense PMMA degradation.

\section{Acknowledgements}

The authors gratefully acknowledge the financial support of the Slovenian Research Agency (programme P1-0175(C)).

\section{References}

1. A. Laachachi, D. Ruch, F. Addiego, M. Ferriol, M. Cochez, J. M. Lopez Cuesta, Polym Degrad Stab. 2009, 94, 670-8. http://dx.doi.org/10.1016/j.polymdegradstab.2008.12.022

2. W. U. Huynh, J. J. Dittmer, A. P. Alivisatos, Sci. 2002, 295, 2425-2427. http://dx.doi.org/10.1126/science.1069156

3. H. Gu, J. Guo, H. Wei, S. Guo, J. Liu, Y. Huang, M. A. Khan, X. Wang, D. P. Young, S. Wei, Z. Guo, Adv. Mater. 2015, 28;27(40), 6277-6282.

4. C. Yang, H. Wei, L. Guan, J. Guo, Y. Wang, X. Yan, X. Zhang, S. Wei, Z. Guo, J. Mater. Chem. A. 2015, 3, 1492914941. http://dx.doi.org/10.1039/C5TA02707A

5. D. Jiang, L. Xing, L. Liu, S. Sun, Q. Zhang, Z. Wu, X. Yan, J. Guo, Y. Huang, Z. Guo, Composites Science and Techno- 
logy. 2015, 117, 168-175

http://dx.doi.org/10.1016/j.compscitech.2015.05.011

6. T. M. Aminabhavi, H. T. S. Phayde, J. D. Ortego, J. M. Vergnaud, Polym. 1996, 37, 1677-1688.

http://dx.doi.org/10.1016/0032-3861(96)83718-9

7. R. L. Ballard, J. P. Williams, J. M. Njus, B. R. Kiland, Eur. Polym. J. 2001, 37, 381-398.

http://dx.doi.org/10.1016/S0014-3057(00)00105-1

8. A. Nair, R. L. White, J. Appl. Polym. Sci. 1996, 60, 1901-1909. http://dx.doi.org/10.1002/(SICI)1097-4628(19960613)60: $11<1901:: A I D-A P P 14>3.0 . C O ; 2-3$

9. J. Brandrup, E. H. Immergut, E. A. Grulke, Polymer handbook 4th ed: Wiley,. New York, 2003, pp 1999.

10. J. W. Gilman, S. J. Ritchie, T. Kashiwagi, S. M. Lomakin, Fire Mater. 1997, 21, 23-32.

http://dx.doi.org/10.1002/(SICI)1099-1018(199701)21: $1<23:$ :AID-FAM591>3.0.CO;2-O

11. T. C. Chang, Y. T. Wang, Y. S. Hong, Y. S. Chiu, J Polym Sci Part A: Poly Chem. 2000, 38, 1972-1980.

http://dx.doi.org/10.1002/(SICI)1099-0518(20000601)38:11 $<1972::$ AID-POLA60>3.0.CO;2-5

12. T. Kashiwagi, A. B. Morgan, J. M. Antonucci, M. R. VanLandingham, R. H. Harris, W. H. Awad, J. R. Shields, J Appl Polym Sci. 2003, 89, 2072-2078. http://dx.doi.org/10.1002/app.12307

13. Y. H. Hu, C. Y. Chen, C. C. Wang, Polym Degrad Stab. 2004, $84,545-553$.

http://dx.doi.org/10.1016/j.polymdegradstab.2004.02.001

14. A. B. Morgan, J. M. Antonucci, M. R. VanLandingham, R. H. Harris, T. Kashiwagi, Polym Mater Sci Eng. 2000, 83, 57-58.

15. F. Yang, G. L. Nelson, J Appl Polym Sci. 2004, 91, 38443850. http://dx.doi.org/10.1002/app.13573

16. A. Aruchamy, K. A. Blackmore, B. J. J. Zelinshi, D. R. Uhlmanm, C. Booth, MRS Proc. 1991, 249, 353-357.

17. A. Laachachi, M. Cochez, M. Ferriol, J. Lopez-Cuesta, E. Leroy, Mater Lett. 2005, 59, 36-39. http://dx.doi.org/10.1016/j.matlet.2004.09.014

18. A. Laachachi, E. Leroy, M. Cochez, M. Ferriol, J. M. Lopez Cuesta, Polym Degrad Stab. 2005, 89, 344-352. http://dx.doi.org/10.1016/j.polymdegradstab.2005.01.019

19. A. Laachachi, M. Ferriol, M. Cochez, D. Ruch, J. M. LopezCuesta, Polym Degrad Stab. 2008, 93, 1131-1137. http://dx.doi.org/10.1016/j.polymdegradstab.2008.03.006

20. Y. Liu, Y. Liu, C. Zhang, H. Tan, X. Yan, H. Wei, Z. Guo, Macromolecular Materials and Engineering. 2015, 300, 6469. http://dx.doi.org/10.1002/mame.201400166

21. E. Tang, G. Cheng, X. Ma, Powder Technol. 2006, 161, 209214. http://dx.doi.org/10.1016/j.powtec.2005.10.007

22. E. Tang, G. Cheng, X. Pang, X. Ma, F. Xing, Colloid Polym Sci. 2006, 284, 422-428. http://dx.doi.org/10.1007/s00396-005-1389-z

23. M. M. Demir, K. Koynov, Ü. Akbey, C. Bubeck, I. Park, I. Lieberwirth, G. Wegner, Macromol. 2007, 40, 1089-1100. http://dx.doi.org/10.1021/ma062184t

24. X. Y. Ma, W. D. Zhang, Polym Degrad Stab. 2009, 94, 11031109. http://dx.doi.org/10.1016/j.polymdegradstab.2009.03.024

25. T. Kos, A. Anžlovar, E. Žagar, Z. Crnjak Orel, M. Žigon, Acta Chim Slov. 2014, 61, 497-505.

26. A. Anžlovar, Z. Crnjak Orel, K. Kogej, M. Žigon, J Nanomater. 2012, 2012, art.no.760872, 9.

27. J. Sharma, X. Zhang, T. Sarker, X. Yan, L. Washburn, H. Qu,. Z. Guo, A. S. Kucknoor, S. Wei, Polymer. 2014, 55, 32613269. http://dx.doi.org/10.1016/j.polymer.2014.05.028

28. Z. L. Wang, J Phys Condens Matter. 2004, 16, R829-58. http://dx.doi.org/10.1088/0953-8984/16/25/R01

29. L. Schmidt-Mende, J. L. MacManus-Driscoll, Mater Today. 2007, 10, 40-48.

http://dx.doi.org/10.1016/S1369-7021(07)70078-0

30. D. Sun, N. Miyatake, H. J. Sue, Nanotechnol. 2007, 18, 215606-215612. http://dx.doi.org/10.1088/0957-4484/18/21/215606

31. P. Liu, Z. Su, J Macromol Sci Part B. 2006, 45, 131-138. http://dx.doi.org/10.1080/00222340500408085

32. M. M. Demir, M. Memesa, P. Castignolles, G. Wegner, Macromol Rapid Commun. 2006, 27, 763-770. http://dx.doi.org/10.1002/marc.200500870

33. S. C. Liufu, H. N. Xiao, Y. P. Li, Polym Degrad Stab. 2005, 87, 103-110.

http://dx.doi.org/10.1016/j.polymdegradstab.2004.07.011

34. J. Du, J. Zhu, C. A. Wilkie, J. Wang, Polym Degrad Stab. 2002, 77, 377-381.

http://dx.doi.org/10.1016/S0141-3910(02)00074-5

35. J. Zhu, F. M. Uhl, A. B. Morgan, C. A. Wilkie, Chem Mater. 2001, 13, 4649-4654. http://dx.doi.org/10.1021/cm010451y

36. B. N. Jang, M. Costache, C. A. Wilkie, Polym. 2005, 46, 10678-10687. http://dx.doi.org/10.1016/j.polymer.2005.08.085

37. D. Japić, I. Djerdj, M. Marinšek, Z. Crnjak Orel, Acta Chim Slov. 2014, 60, 797-806.

38. S. Liu, L. Lu, Z. Yang, P. Cool, E. F. Vansant, Mater Chem Phys. 2006, 97, 203-206. http://dx.doi.org/10.1016/j.matchemphys.2005.09.003

39. S. Vyazovkin, J Therm Anal. 1997, 49, 1493-1499. http://dx.doi.org/10.1007/BF01983708

40. Y. Grohens, J. Schultz, R.E. Prud'homme, Int J Adhes Adhes. 1997, 17, 163-167. http://dx.doi.org/10.1016/S0143-7496(96)00035-8

41. I. C. McNeill, M. H. Mohammed, Polym Degrad Stab. 1995, 48, 189-195. http://dx.doi.org/10.1016/0141-3910(95)00031-G

42. S. Zulfigar, K. Masud, Polym Degrad Stab. 2002, 78, 305313. http://dx.doi.org/10.1016/S0141-3910(02)00176-3

43. T. C. K. Yang, S. S.Y. Lin, T. H. Chuang, Polym Degrad Stab. 2002, 78, 525-532. http://dx.doi.org/10.1016/S0141-3910(02)00225-2 


\section{Povzetek}

$\mathrm{Z}$ uporabo termoanalitskih tehnik je bila določena vloga nanodelcev $\mathrm{ZnO}$ pri termični dekompoziciji polimetilmetakrilata (PMMA). Za študij sistema ZnO/PMMA smo uporabili tehnike TG, DTA, EGA, XRD, SEM in TEM. Nanodelci $\mathrm{ZnO}$ so bili sintetizirani s precipitacijsko metodo $\mathrm{z}$ dodajanjem $\mathrm{LiOH}$ v raztopino $\mathrm{Zn}^{2+} \mathrm{v}$ mešanici topil $\mathrm{H}_{2} \mathrm{O}$ in etilenglikol. Nanokompoziti ZnO/PMMA so bili pripravljeni z ustreznim dodatkom ZnO v MMA in kasnejšo radikalsko polimerizacijo MMA. Glede na rezultate testov in kinetične izračune aktivacijske energije termičnega razpada PMMA, ima dodatek ZnO v PMMA dvojno vlogo. Dodatek ZnO v PMMA do 0,15\% stabilizira kompozit, saj premakne temperaturno okno razpada kompozita k višjim vrednostim in hkrati zviša aktivacijsko energijo termičnega razpada PMMA. Obratno, dodatek ZnO nad 0,15\% v ZnO/PMMA kompozitu na razpad PMMA deluje katalitsko, saj zniža aktivacijsko energijo termičnega razpada PMMA in hkrati premakne temperaturno okno razpada kompozita k nižjim vrednostim. Dodatek $\mathrm{ZnO}$ ne spremeni mehanizma razpada PMMA. 